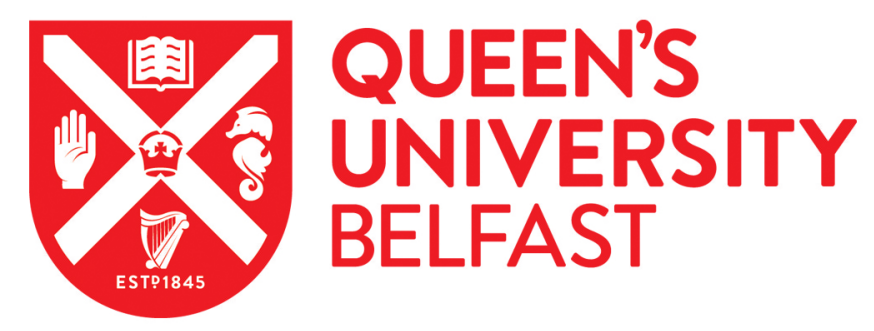

\title{
Supramolecular gelation as the first stage in Ostwald's rule
}

Andrews, J. L., Pearson, E., Yufit, D. S., Steed, J. W., \& Edkins, K. (2018). Supramolecular gelation as the first stage in Ostwald's rule. Crystal Growth and Design. https://doi.org/10.1021/acs.cgd.8b01539

\author{
Published in: \\ Crystal Growth and Design
}

Document Version:

Peer reviewed version

Queen's University Belfast - Research Portal:

Link to publication record in Queen's University Belfast Research Portal

Publisher rights

Copyright $\odot 2018$ American Chemical Society. This work is made available online in accordance with the publisher's policies. Please refer to any applicable terms of use of the publisher.

\section{General rights}

Copyright for the publications made accessible via the Queen's University Belfast Research Portal is retained by the author(s) and / or other copyright owners and it is a condition of accessing these publications that users recognise and abide by the legal requirements associated with these rights.

Take down policy

The Research Portal is Queen's institutional repository that provides access to Queen's research output. Every effort has been made to ensure that content in the Research Portal does not infringe any person's rights, or applicable UK laws. If you discover content in the Research Portal that you believe breaches copyright or violates any law, please contact openaccess@qub.ac.uk. 


\title{
COVER PAGE:
}

\section{Supramolecular gelation as the first stage in Ostwald's rule}

Jessica L. Andrews ${ }^{[\mathrm{a}]}$, Emma Pearson ${ }^{[\mathrm{b}]}$, Dmitry S. Yufit ${ }^{[\mathrm{a}]}$, Jonathan W. Steed ${ }^{[\mathrm{a}]}$ and Katharina Edkins*[c]

a) Department of Chemistry, Durham University, South Road, Durham, DH1 3LE, UK. b)

School of Medicine, Pharmacy and Health, Durham University, University Boulevard, Stocktonon-Tees, TS17 6BH, UK. c) School of Pharmacy, Queen's University Belfast, 97 Lisburn Road, Belfast, BT9 7BL, UK.

\section{Corresponding Author:}

Dr Katharina Edkins

School of Pharmacy, Queen's University Belfast, 97 Lisburn Road, Belfast, BT9 7BL, UK

k.edkins@qub.ac.uk

\begin{abstract}
:
Ostwald's rule of stages describes the observation that a metastable polymorph of a particular compound will crystallise before the thermodynamically stable form under the same conditions. Whilst traditionally applied to crystalline systems, there have been recent examples in which non-crystalline supramolecular assemblies transform according to this rule. In this work we report the highly selective organogelation behaviour of a mono-iodinated 2,4,5triphenylimidazole (lophine) derivative (I-TPI). The gel emerges as a kinetically trapped intermediate, prior to the crystallisation of a series of increasingly stable methanol solvates. As such, we describe the supramolecular gel as a pre-crystalline phase, representing the first of Ostwald's stages for this system. Similar behaviour can be observed when the gel is used as a medium for pharmaceutical crystallisation of diatrizoic acid (DTA). In this case, two solid forms are produced, both containing molecules of DTA, I-TPI and methanol in different stoichiometries, and once again crystallising in sequence according to Ostwald's rule. These results demonstrate that supramolecular gelation may be considered the first stage in the stepwise crystallisation of a gelator, as governed by Ostwald's rule, and that this behaviour also applies to multi-component systems, facilitating the production of metastable pharmaceutical solid forms.
\end{abstract}

\section{Key Illustration:}

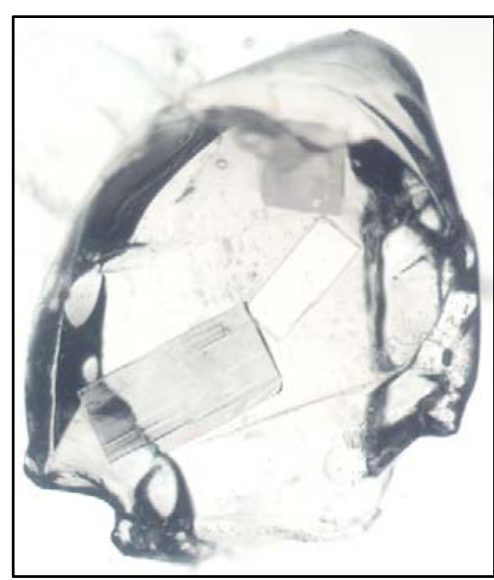




\section{Supramolecular gelation as the first stage in}

\section{Ostwald's rule}

Jessica L. Andrews ${ }^{[a]}$, Emma Pearson ${ }^{[b]}$, Dmitry S. Yufit ${ }^{[a]}$, Jonathan W. Steed ${ }^{[a]}$ and Katharina Edkins*[c]

a) Department of Chemistry, Durham University, South Road, Durham, DH1 3LE, UK. b) School of Medicine, Pharmacy and Health, Durham University, University Boulevard, Stocktonon-Tees, TS17 6BH, UK. c) School of Pharmacy, Queen's University Belfast, 97 Lisburn Road, Belfast, BT9 7BL, UK.

ABSTRACT: Ostwald's rule of stages describes the observation that a metastable polymorph of a particular compound will crystallise before the thermodynamically stable form under the same conditions. Whilst traditionally applied to crystalline systems, there have been recent examples in which non-crystalline supramolecular assemblies transform according to this rule. In this work we report the highly selective organogelation behaviour of a mono-iodinated 2,4,5triphenylimidazole (lophine) derivative (I-TPI). The gel emerges as a kinetically trapped intermediate, prior to the crystallisation of a series of increasingly stable methanol solvates. As such, we describe the supramolecular gel as a pre-crystalline phase, representing the first of Ostwald's stages for this system. Similar behaviour can be observed when the gel is used as a 
medium for pharmaceutical crystallisation of diatrizoic acid (DTA). In this case, two solid forms are produced, both containing molecules of DTA, I-TPI and methanol in different stoichiometries, and once again crystallising in sequence according to Ostwald's rule. These results demonstrate that supramolecular gelation may be considered the first stage in the stepwise crystallisation of a gelator, as governed by Ostwald's rule, and that this behaviour also applies to multi-component systems, facilitating the production of metastable pharmaceutical solid forms.

\section{INTRODUCTION}

Crystallisation is defined as the phase transition from a fluid or solution to a highly ordered solid $^{1}$, and is of utmost importance in a range of industries, including pharmaceuticals, fine chemicals, and food. In fact, the vast majority of all chemical processes include a crystallisation step, because this method allows the convenient separation and purification of a product. $^{2}$ Throughout many decades of work in this field, a range of empirical rules have emerged, acting as general guidelines to predict and characterise the result of a crystallisation process. ${ }^{3}$ A notable example is Ostwald's rule of stages, which refers to the observation that a metastable polymorph will often crystallise from solution before the form that is most thermodynamically stable under the same conditions. ${ }^{4}$ The classic example is benzamide, in which the least stable form, orthorhombic form II, is initially produced by flash cooling, followed by the monoclinic form III, and finally, the most stable form, monoclinic form I. ${ }^{5}$ Metastable crystal forms are kinetically favoured compared to the thermodynamically stable form. Because nucleation is the critical step in a crystallisation process and is also kinetically controlled, the crystallisation process progresses towards equilibrium via a series of kinetically favoured, metastable polymorphs. Traditionally, this rule has been applied to purely crystalline systems, but recent work suggests that the formation of supramolecular materials can also follow Ostwald's rule. ${ }^{6}$ It is therefore 
plausible that the rule holds true for the breakdown of other supramolecular systems, such as low molecular weight gels.

Gels are an extremely common form of soft matter consisting of a three-dimensional fibrillar network, which immobilise the fluid phase by surface tension. ${ }^{7}$ The resulting, solid-like material is capable of supporting its own weight under the 'inversion test' and can be identified by characteristic viscoelastic behaviour. ${ }^{8}$ Gelators are commonly polymeric, but there is considerable recent interest in low molecular weight, supramolecular gels, which rely on noncovalent interactions between small molecules to form the gel network. ${ }^{9-10}$ Formation of a smallmolecule supramolecular gel requires the organisation of molecules into a low-dimensional aggregate, such as a fibril ${ }^{11}$ or scrolled sheet. ${ }^{12}$ This behaviour is most commonly displayed by molecules whose non-covalent interactions are strongest in one direction, ${ }^{11}$ such as ureas or amides which provide strong, directional $\mathrm{NH} \cdots \mathrm{O}=\mathrm{C}$ hydrogen bonds. ${ }^{13-14}$

It is well known that gelation and crystallisation are two closely related self-assembly processes. ${ }^{15}$ Although this relationship is not sufficiently well understood to allow the rational design of a molecule which will preferentially gel or crystallise, significant work is underway in this area. Theoretical and computational studies have probed the stability relationships between gels and crystals, ${ }^{16-17}$ whilst empirical studies on gels which exhibit the gradual formation of microcrystals have probed systems existing right on the boundary between gelation and crystallisation. ${ }^{18-20}$ In some cases, crystals have been observed to grow directly from the gel. Despite originally being thought of as extremely rare, this phenomenon has recently been observed with increasing frequency, and within a chemically diverse range of both hydro- and organogels. $^{21-28}$ It is important that this phenomenon, and the balance between gelation and crystallisation in general, are thoroughly understood, because the ability to precisely control 
these processes would be of significant use in chemical industry. For example, the antibiotic drug cefpiramide has been observed to form an organogel which is stable for several days before it breaks down and crystallises. ${ }^{29}$ This behaviour is by no means unique to this drug, ${ }^{30}$ and is highly undesirable for large-scale manufacturing because it reduces the time and cost efficiency of the process.

Sterically hindered 2,4,5-triphenylimidazole derivatives have classically been exploited for their luminescence properties, allowing them to be used as versatile analytical probes..$^{31-32}$ Similarly, lophine radicals have been shown to exhibit photo-, thermo-, and piezo-chromism through the formation of reversible dimers. ${ }^{33}$ These materials therefore lend themselves to application in display technologies, and chemical or molecular switches. ${ }^{34-36}$ In previous work, we studied a series of mono-halogenated 2,4,5-triphenylimidazole derivatives (Fig. 1) and showed that changing the substituent in a single position has a significant effect on the solid state structure and properties of these materials. ${ }^{37}$ A key finding was that there was a much more significant change in properties between the chloro- and bromo- derivatives, than between any other adjacent pair in the series.

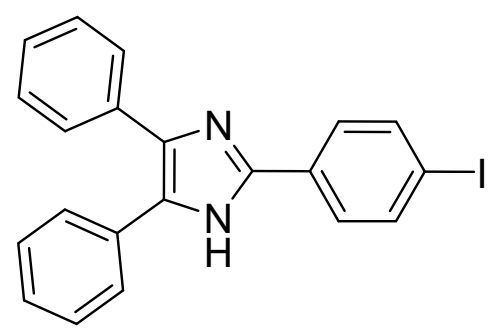

Figure 1. Structure of the mono-iodinated 2,4,5-triphenyl imidazole derivative (I-TPI).

In all cases, the crystal structures contained hydrogen-bonded chains of imidazole units, which is the dominant motif observed in other imidazole derivatives. ${ }^{37-40}$ All studied halogenated TPI derivatives formed methanol solvates, and in this case, the solvent intercalates into the imidazole 
hydrogen-bonded chains. ${ }^{37}$ Our previous work characterised the methanol solvates of all halogenated TPI derivatives by powder X-ray diffraction (PXRD) and reported single-crystal structures for the fluoro- and bromo-TPI solvates. These layered structures were closely related but revealed a shift in the layers due to the increasing size of the halogen substituent. Two anhydrous polymorphs of each TPI derivative were also characterised by PXRD and, for the methanol solvates, the desolvated form showed no structural similarity to its solvate.

During this study, we observed gel formation with the I-TPI analogue in methanol. Whilst imidazole functionalities have been incorporated into gelators before, ${ }^{41-44}$ they are rarely the functional group solely responsible for gelation. Imidazole derivatives by themselves typically prefer to crystallise, often forming $\mathrm{NH} \cdots \mathrm{N}$ hydrogen bonds between molecules. ${ }^{40} \mathrm{We}$ hypothesised that, in the case of I-TPI, gelation is driven by the unidirectional hydrogen bonding motif of the imidazole groups, coupled with weaker interactions perpendicular to the hydrogen bond axis, caused by the peripheral aromatic rings and the large size of the halogen substituent. We also observed spontaneous crystallisation of this gel, forming a series of distinct polymorphs, one after the other. We now report a detailed study on I-TPI, in order to probe the balance between its gel formation and crystallisation. We propose that this system behaves as an unusual example of Ostwald's rule of stages.

\section{RESULTS AND DISCUSSION}

\section{Characteristics of the I-TPI Gel}

The gelation behaviour of I-TPI was first noted in methanol, in which a stable and optically transparent gel is formed from a supersaturated solution, heated to $65^{\circ} \mathrm{C}$ and then left cool under ambient conditions for ten minutes (Fig. 2a). The gel is thermoreversible, meaning it will 
dissolve when heated and reform when cooled a second time. However, it is not thixotropic and therefore will not reform after being broken down by mechanical stress. SEM images of the dried xerogel demonstrate an unusual morphology, composed of short aggregates with dimensions $c a$. $0.5 \times 0.05 \mu \mathrm{m}$, which explains why the gel is transparent in visible light (Fig. 2b).

(a)

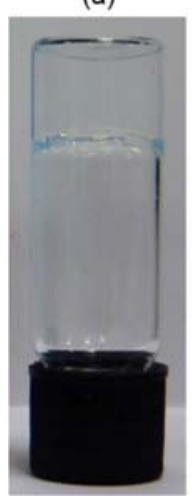

(b)

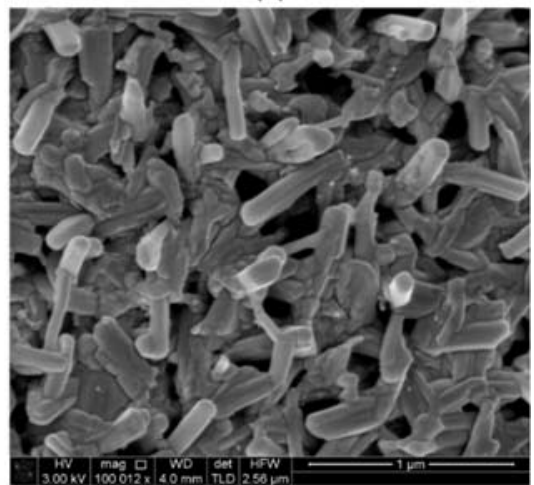

Figure 2. (a) Photograph of a $2 \%$ w/v I-TPI gel, showing its optical transparency. (b) SEM micrograph of a $2 \% \mathrm{w} / \mathrm{v}$ I-TPI xerogel.

The blocky morphology in the I-TPI gel differs considerably from the long intertwined fibres typical of a supramolecular gel, ${ }^{8,45}$ but it is possible this may be artefact from drying the native gel. ${ }^{46-47}$ Because this gel was known to crystallise, a series of SEM images were recorded at different magnifications to confirm that the gel morphology was consistent throughout the sample (Fig. S2a,b,c), and that it differed from that of a crystal (Fig. S2d,e). Whilst the gel morphology does differ significantly from that of a macroscopic crystal, its blocky appearance suggests some degree of crystallinity. It is possible that the very early stages of the gel to crystal transition occurred during the drying process, leading to this unusual morphology.

The gelation behaviour of I-TPI was then tested in a wide range of solvents. A $2 \% \mathrm{w} / \mathrm{v}$ solution of I-TPI in the test solvent was heated to the boiling point of the solvent in a sealed glass vial, left to cool to room temperature, and monitored for gelation or crystal growth. Of 47 
solvents tested, gelation was only observed in methanol over a small range of concentrations. By cooling under ambient conditions, the critical gelling concentration (CGC) in methanol, determined by the inversion test, is $1.9 \% \mathrm{w} / \mathrm{v}$ but can be reduced to $1.25 \% \mathrm{w} / \mathrm{v}$ by sonication or crash cooling in ice, in which cases the gel forms in a reduced time of five minutes. This finding fits well with the hypothesis that the gel is favoured by Ostwald's rule. Full results from the gelation testing in methanol are given in Table S1.

Oscillatory rheology probes the mechanical properties of the gel. Frequency sweep data from a $2 \% \mathrm{w} / \mathrm{v}$ gel show the storage modulus to be approximately one order of magnitude greater than the loss modulus, demonstrating the elastic behaviour characteristic of a gel (Fig. 3). ${ }^{48}$ The yield stress of the gel, used to quantify its strength, can be estimated from stress sweep rheology as the oscillation stress at which the storage and loss moduli are equal. In the case of a $2 \% \mathrm{w} / \mathrm{v}$ I-TPI gel, a yield stress of $c a .300$ Pa proves the material to be quite robust (Fig 3). ${ }^{49}$

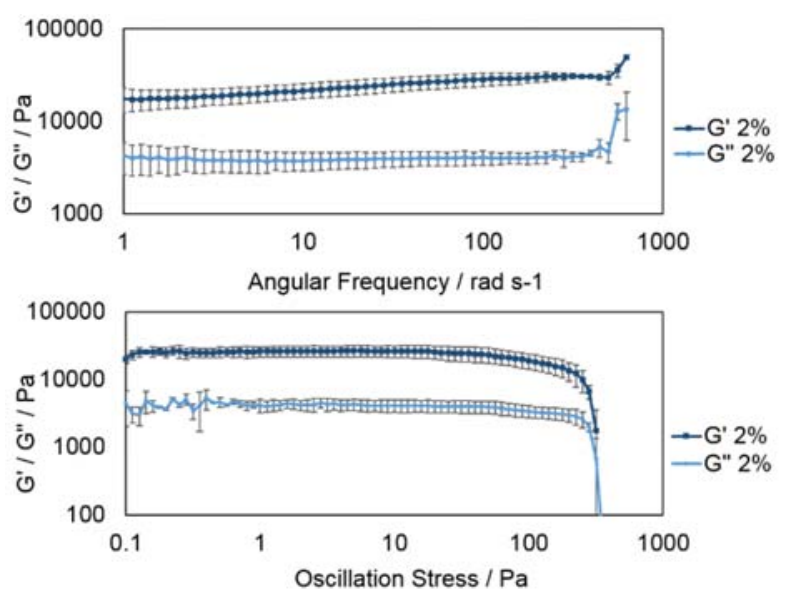

Figure 3. Oscillatory frequency (top) and stress (bottom) sweeps for a $2 \% \mathrm{w} / \mathrm{v}$ I-TPI gel, showing linear viscoelastic behaviour under increasing frequency and a yield stress of ca. 300 Pa. Error bars indicate the standard deviation from repeated measurements. 
Gels with a lower concentration of gelator are weaker than those with higher concentrations. Whilst this trend is subtle, due to the narrow concentration range over which gelation is observed, the elastic behaviour characteristic of a supramolecular gel was observed consistently over the whole range of concentrations (Figures S3 and S4).

If stored, the I-TPI gel breaks down yielding large, block-shaped single crystals (Fig. 4). The length of time taken for this crystallisation to occur is variable due to the inconsistent nature of nucleation processes, however general trends can be established depending on the storage conditions of the gel. If left undisturbed and at a constant temperature, some gels were stable for several months, whilst crystallisation occurred more commonly between one day and two weeks. The effect could be accelerated to occur between five minutes and three hours through any kind of mechanical agitation of the gel, including shaking, cutting, stirring or an oscillatory rheology experiment. The more the gel was disrupted, the more quickly it crystallised. The crystals forming reproducibly were identified by single-crystal X-ray diffraction as a 1:1 methanol solvate, termed Form SI, in which the ' $\mathrm{S}$ ' denotes that the structure is a solvate.

\section{Incorporating Crystallisation Additives}

Based on a large body of previous work into additive-mediated crystallisation, ${ }^{50-52}$ the crystallisation behaviour of the I-TPI gel was further investigated through incorporation of a chemically diverse range of additives. Previous studies have shown crystallisation additives to have a variety of different effects, notably including suppression of the kinetically stable forms favoured by Ostwald's rule to promote production of a desired thermodynamic polymorph. ${ }^{53-56}$ The additives used in this study were 1,4-diiodobenzene, pyrene, 1-aminopyrene and tetrabutylammonium (TBA) chloride (Table S2), as they show a wide range of potential interaction modes with the gelator that could lead to the suppression of the kinetically favoured 
gel phase. ${ }^{57}$ For solid additives, gels were prepared by dissolving the required additive at concentrations ranging from $0.4-8 \% \mathrm{w} / \mathrm{v}$ in a $2 \% \mathrm{w} / \mathrm{v}$ solution of I-TPI in methanol before cooling to room temperature. Gelation of solvent mixtures was also investigated, with methanol mixtures containing between 1-14 v/v of hexane, water or DMSO. In all additive-containing gels, except those including TBA chloride, crystallisation was observed within the intact gel over the course of one hour to one week, depending on the nature of the solvent mixture. These crystals were large plates; a noticeably different morphology to the block-shaped crystals of Form SI (Fig. 4).

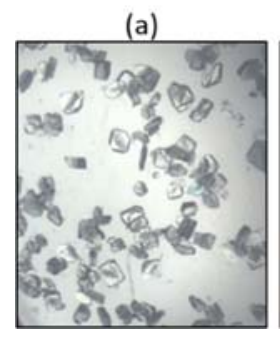

(b)

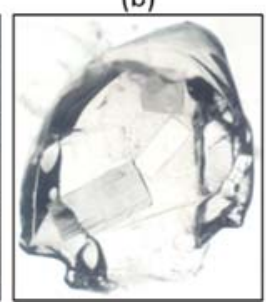

(c)

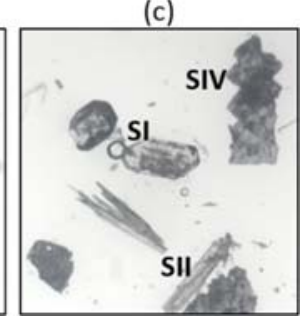

Figure 4. (a) Morphology of the Form SI crystals, (b) crystals of Form SII grown within a gel containing $5 \mu \mathrm{L}$ of DMSO, (c) the concomitant crystallisation of Forms SI, SII and SIV from a gel containing $10 \mathrm{mg}$ of 1,4-diiodobenzene.

Single-crystal X-ray diffraction was used to characterise a crystal from each of eighteen different gels and in every case except one, the crystals were identified as a second 1:1 methanol solvate, Form SII. The exceptional case occurred from the incorporation of 1,4-diiodobenzene into the gel, which caused concomitant crystallisation of Forms SI, SII and a further unidentified form termed Form SIV (Fig. 4). In addition to the incorporation of additives, the growth of Form SII crystals within the gel can be also triggered by forming the gel very quickly in ice, which increases the supersaturation of the solution. Or, by repeatedly heating and reforming the material, which ensures all seeds and nucleation sites for Form SI are removed and allows Form 
SII to form. This behaviour points towards the metastable character of Form SII, as per Ostwald's rule.

All gels in which Form SII was crystallised broke down over a time period ranging from one hour to three days after crystal formation, which was much quicker than the pure $2 \% \mathrm{w} / \mathrm{v}$ material. The dissolution of these gels was likely caused by the incorporation of gelator molecules into the crystals causing the solution concentration to drop below the critical point required for gelation. Following breakdown of the gel, the crystals of Form SII consistently transform into Form SI, either within the mother liquor or when removed and stored under ambient conditions. These observations imply that Form SI is more stable than Form SII.

Rheological characterisation of gels containing DMSO, hexane and TBA chloride allows quantification of the effect these additives or mixed media have on the gel. DMSO and hexane were selected for more detailed analysis because they have opposite effects on the solubility of the gelator, and should therefore represent two extremes of behaviour. ${ }^{58}$ Increasing the concentration of DMSO in the solvent mixture from 2 to $6 \% \mathrm{v} / \mathrm{v}$ caused a decrease in elastic and viscous moduli, $\mathrm{G}^{\prime}$ and $\mathrm{G}^{\prime \prime}$ respectively, and a decrease in yield stress (Fig. S5). This behaviour is consistent with the increasing solubility of the gelator in the DMSO-containing solvent mixture, which inhibits the formation of solid-like gel fibres. Increasing the concentration of hexane in the solvent mixture from 2 to $6 \% \mathrm{v} / \mathrm{v}$ produced little variation in shear moduli, but in this case an increase in yield stress was observed (Fig. S7). Due to the low solubility of I-TPI in hexane, this gel was observed to crystallise on the timescale of a rheology experiment (ca. two hours). One possible explanation of this behaviour may be the formation of solid particles within the gel, as small crystallites begin to grow. ${ }^{59}$ TBA chloride-containing gels were selected for rheological characterisation because the addition of anions has typically been shown to disrupt 
gelation. ${ }^{60-63}$ The opposite seemed to be true in this case, because these chloride-containing gels remained stable for much longer than any other gel tested and at sufficient chloride concentration, were not observed to crystallise at all. A decreasing yield stress was observed as the concentration of TBA chloride was increased from 2 to $6 \% \mathrm{w} / \mathrm{v}$. This behaviour is consistent with a high concentration of anions disrupting the hydrogen-bonded network as previously reported. ${ }^{60-63}$ However, in this case, there was no significant effect on the shear moduli with increasing concentration of chloride (Fig. S6).

Regardless of the concentration of additive that was incorporated, inclusion of DMSO, hexane or TBA chloride all produced a small but reproducible trend towards higher shear moduli and yield stress than the pure gelator in methanol. A representative example is shown in Figure S8, comparing the $2 \% \mathrm{w} / \mathrm{v}$ pure I-TPI/methanol gel to gels containing $2 \% \mathrm{w} / \mathrm{v}$ I-TPI and either $2 \%$ $\mathrm{w} / \mathrm{v}$ TBA chloride, or $2 \% \mathrm{v} / \mathrm{v}$ hexane or DMSO. I-TPI is insoluble in hexane, and therefore, the increase in strength of this gel is likely due to the formation of more gel fibres, because the solution is more supersaturated. DMSO can accept multiple hydrogen bonds and may form lateral links between gel fibres, causing greater entanglement of the gel network and increasing its strength relative to the pure material; a phenomenon commonly observed when polymers or surfactants are incorporated into supramolecular gels. ${ }^{64-67}$ Finally, the incorporation of anions into supramolecular gels has been reported to have both strengthening ${ }^{68-70}$ and weakening effects, ${ }^{60-63}$ depending on the gelator in question. This anion-tuning behaviour has commonly been observed in urea-based gelators and has been attributed to the anions either promoting ${ }^{68-69}$ or disrupting ${ }^{60-63}$ formation of the urea-tape motif which is responsible for gelation in these materials. One notably different example concerns the anion-triggered gelation of a calix[4]arene 
derivative, rationalised using the Hofmeister series. ${ }^{70}$ In this case, the chloride ions may cause a salting out effect, ${ }^{71-72}$ prompting the formation of more gel fibres and strengthening the gel.

A qualitative assessment, carried out by observing all the additive-containing gels over time, showed that the rate of formation of Form SII crystals within the gels is affected by the chemical nature of the additive. Solvent mixtures containing DMSO crystallised much more slowly, over a minimum of two days, than those containing hexane and water, in which Form SII grew within three hours. This trend is to be expected given the high solubility of I-TPI in polar organic solvents. Hydrogen-bonding additives noticeably slowed the rate of crystallisation, as did the incorporation of TBA chloride. The chloride-containing gels were particularly stable and did not crystallise throughout the entire duration of this work, or about a year.

\section{Crystal Structures of I-TPI}

Further investigation into the crystallisation behaviour of I-TPI led to the discovery of three further solid forms, in addition to the two solvates SI and SII obtained from the gel phase. When paper fibres were serendipitously included into a $2 \% \mathrm{w} / \mathrm{v}$ solution of I-TPI in methanol, gelation was inhibited and large single crystals grew on the fibres. These were identified by single-crystal X-ray diffraction as a third methanol solvate polymorph, Form SIII. Attempts to reproduce this form have been repeatedly unsuccessful, despite the incorporation of a wide range of solid particles to the gel, including paper fibres, microcrystalline cellulose, silica gel, and PVA beads. These difficulties suggest that Form SIII has an extremely high energy barrier to nucleation or is highly metastable, immediately converting to or outgrown by a more stable polymorph. ${ }^{73}$

High-temperature crystallisations were also undertaken, aiming to produce the anhydrous forms identified in previous work by PXRD. ${ }^{37}$ Two non-solvated forms (Forms V and VI) were successfully identified and fully characterised by single-crystal X-ray diffraction. Form V was 
crystallised from pure methanol at $50{ }^{\circ} \mathrm{C}$, a condition under which the gel did not form, even at sufficient concentration. Finally, Form VI was produced by sublimation, a technique which was used to investigate the crystallisation behaviour of I-TPI in the absence of methanol. The crystallographic data for all five crystal forms of I-TPI identified in this work are given in Table 1.

Table 1. Crystallographic data for the novel polymorphs of I-TPI

\begin{tabular}{|c|c|c|c|c|c|c|}
\hline Crystal Form & Form SI & Form SII & Form SIII & Form SIV & Form V & Form VI \\
\hline Formula & $\mathrm{C}_{21} \mathrm{H}_{15} \mathrm{IN}_{2} \cdot \mathrm{CH}_{3} \mathrm{OH}$ & $\mathrm{C}_{21} \mathrm{H}_{15} \mathrm{IN}_{2} \cdot \mathrm{CH}_{3} \mathrm{OH}$ & $\mathrm{C}_{21} \mathrm{H}_{15} \mathrm{IN}_{2} \cdot \mathrm{CH}_{3} \mathrm{OH}$ & & $\mathrm{C}_{21} \mathrm{H}_{15} \mathrm{IN}_{2}$ & $\mathrm{C}_{21} \mathrm{H}_{15} \mathrm{IN}_{2}$ \\
\hline $\operatorname{Mr}\left(\mathrm{g} \mathrm{mol}^{-1}\right)$ & 454.29 & 454.29 & 454.29 & & 422.25 & 422.25 \\
\hline Space group & $\mathrm{P} 2_{1} / \mathrm{c}$ & $\mathrm{P} 2_{1} / \mathrm{c}$ & $\mathrm{P} 2{ }_{1}$ & & $\mathrm{P} 2{ }_{1}$ & $\mathrm{P} \overline{1}$ \\
\hline $\mathrm{a} / \AA ̊$ & $12.6617(9)$ & $6.0855(4)$ & $14.6682(12)$ & $6.209(5)$ & $8.9217(7)$ & $8.9006(8)$ \\
\hline $\mathrm{b} / \AA$ & $12.6076(11)$ & $11.5907(8)$ & $12.0909(10)$ & 13.991(8) & $32.728(2)$ & $11.9043(11)$ \\
\hline $\mathrm{c} / \AA \AA$ & $12.7502(10)$ & $27.2602(16)$ & 17.3887(14) & $22.072(25)$ & $11.9118(9)$ & $33.334(3)$ \\
\hline$\alpha /^{\circ}$ & 90 & 90 & 90 & $103.79(3)$ & 90 & $81.404(3)$ \\
\hline$\beta /{ }^{\circ}$ & 109.0495(19) & $92.0935(19)$ & $110.237(3)$ & $92.3(5$ & $94.579(3)$ & $82.994(3)$ \\
\hline$\gamma /{ }^{\circ}$ & 90 & 90 & 90 & $91.35(4)$ & 90 & $85.467(3)$ \\
\hline $\mathrm{V} / \AA^{3}$ & 1923.9(3) & $1921.5(2)$ & $2893.5(4)$ & 1910(3) & $3467.0(5)$ & $3459.5(5)$ \\
\hline Z & 4 & 4 & 6 & $\begin{array}{l}\text { Unit cell } \\
\text { only }\end{array}$ & 8 & 8 \\
\hline$\rho_{\text {calc }}\left(\mathrm{g} \mathrm{cm}^{-3}\right)$ & 1.568 & 1.570 & 1.564 & & 1.618 & 1.621 \\
\hline $\begin{array}{l}\text { Independent } \\
\text { reflections }\end{array}$ & $\begin{array}{l}3769\left[\mathrm{R}_{\text {int }}=\right. \\
0.0299]\end{array}$ & $\begin{array}{l}4115\left[\mathrm{R}_{\mathrm{int}}=\right. \\
0.0971]\end{array}$ & $\begin{array}{l}13959\left[\mathrm{R}_{\text {int }}=\right. \\
0.1016]\end{array}$ & & $\begin{array}{l}18393\left[\mathrm{R}_{\text {int }}=\right. \\
0.0656]\end{array}$ & $\begin{array}{l}18359\left[\mathrm{R}_{\text {int }}=\right. \\
0.1075\end{array}$ \\
\hline $\begin{array}{l}\text { Goodness-of-fit } \\
\text { on } F^{2}\end{array}$ & 1.075 & 1.080 & 1.029 & & 1.048 & 1.038 \\
\hline $\begin{array}{l}\text { Final } R \text { indexes } \\
{[I>=2 \sigma(I)]}\end{array}$ & $\begin{array}{l}\mathrm{R}_{1}=0.0244 \\
\mathrm{wR}_{2}=0.0548\end{array}$ & $\begin{array}{l}\mathrm{R}_{1}=0.0558 \\
\mathrm{wR}_{2}=0.0817\end{array}$ & $\begin{array}{l}\mathrm{R}_{1}=0.0643 \\
\mathrm{wR}_{2}=0.1294\end{array}$ & & $\begin{array}{l}\mathrm{R}_{1}=0.0546 \\
\mathrm{wR}_{2}=0.1232\end{array}$ & $\begin{array}{l}\mathrm{R}_{1}=0.0785 \\
\mathrm{wR}_{2}=0.1705\end{array}$ \\
\hline $\begin{array}{l}\text { Final } R \text { indexes } \\
\text { [all data] }\end{array}$ & $\begin{array}{l}\mathrm{R}_{1}=0.0351 \\
\mathrm{wR}_{2}=0.0601\end{array}$ & $\begin{array}{l}\mathrm{R}_{1}=0.1094 \\
\mathrm{wR}_{2}=0.0940\end{array}$ & $\begin{array}{l}\mathrm{R}_{1}=0.1161 \\
\mathrm{wR}_{2}=0.1459\end{array}$ & & $\begin{array}{l}\mathrm{R}_{1}=0.0667 \\
\mathrm{wR}_{2}=0.1296\end{array}$ & $\begin{array}{l}\mathrm{R}_{1}=0.1333 \\
\mathrm{wR}_{2}=0.1903\end{array}$ \\
\hline
\end{tabular}


A full structure of Form SIV could not be obtained due to poor crystal quality, but the unit cell volume is consistent with a methanol monosolvate. ${ }^{74}$ The cell dimensions also match closely with the other three solvates, which adds weight to this hypothesis. The crystal structures of imidazole derivatives are typically characterised by chains of imidazole units, connected by $\mathrm{NH} \cdots \mathrm{N}$ hydrogen bonds. ${ }^{37,40}$ This arrangement is observed in both anhydrous polymorphs of ITPI, Forms V and VI (Fig. 5).
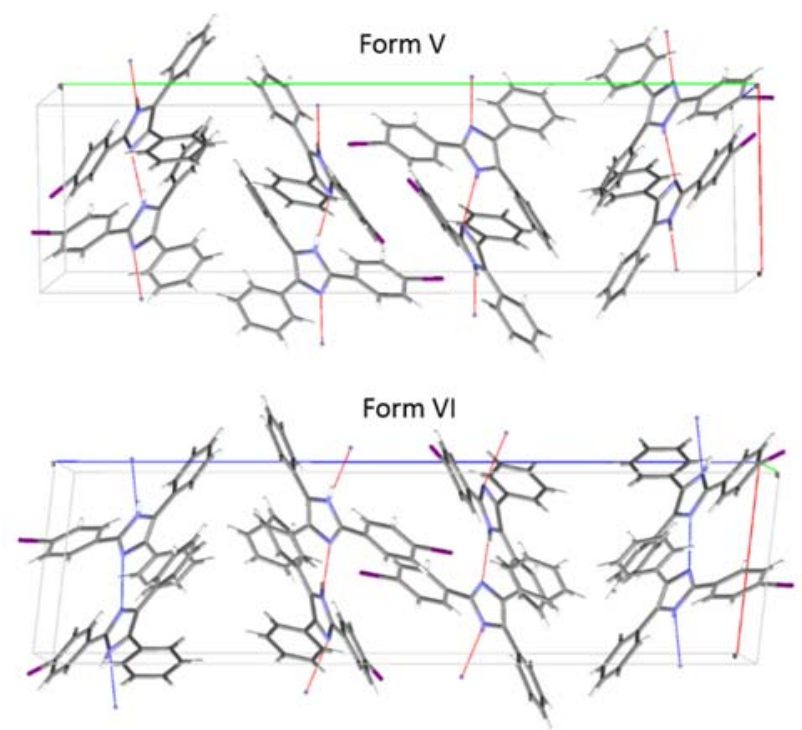

Figure 5. Hydrogen-bonded chains in Forms V and VI of I-TPI.

For both structures V and VI, there are four independent molecules per asymmetric unit and there are four different $\mathrm{NH} \cdots \mathrm{N}$ hydrogen bonds in each structure. The average $\mathrm{N} \cdots \mathrm{N}$ distance in both forms is $2.9 \AA$, which is typical for a substituted imidazole. ${ }^{75}$ In I-TPI, steric interactions between the bulky phenyl substituents cause the imidazole rings to twist out of plane with each other, as was observed in other sterically hindered lophine derivatives. ${ }^{40}$ Both structures have a 
high $Z^{\prime}$ of 4 which suggests some degree of awkwardness in their packing. A significant correlation has been found between $Z^{\prime}>1$ 'parent' phases and solvate or co-crystal formation, and may explain the prevalence of solvates in this system. ${ }^{76-77}$

Although the basic packing motif of both anhydrous polymorphs are essentially the same, the stacking of these motifs shows a subtle difference (Fig. 6).

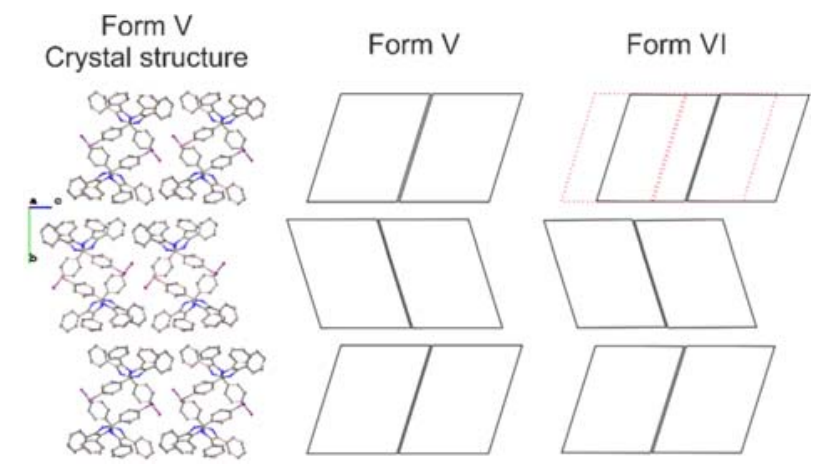

Figure 6. Packing arrangement of Form V crystal structure viewed along the crystallographic $a$ axis, schematic representation of form $\mathrm{V}$ of the same view, and schematic of Form VI viewed along the crystallographic $a$ axis. The red dotted overlay in the schematic of Form VI represents the deviation in packing observed in Form V.

Both crystal forms display layered packing when viewed along the respective crystallographic $a$ axis. The layers contain the typical hydrogen-bonded chains, in which two are packed together to form strands stabilised by $\pi$-stacking of the iodo-phenyl moieties. Each double strand is represented by a rhomboid to simplify the stacking of the crystal structure. This schematic representation shows that a shift in the layers occurs in Form VI compared to Form V, based on the different symmetry of the crystal forms. Whilst in Form $\mathrm{V}$ the layers are related through the 21 -screw axis resulting in the monoclinic cell of the crystal structure, Form VI shows only the 
inversion centre of the triclinic space group $\mathrm{P} \overline{1}$. The latter results in a larger shift of every third layer against the first when compared to Form V. Such small difference in packing of polymorphs has been shown for other compounds, e.g. $\operatorname{aspirin}^{78}$ or larger supramolecular assemblies such as calix[4]arene. ${ }^{79}$

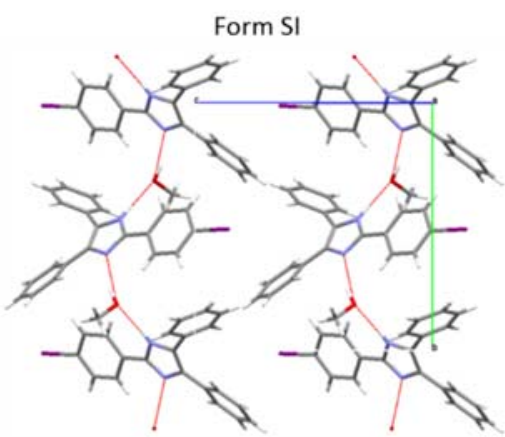

Form SII
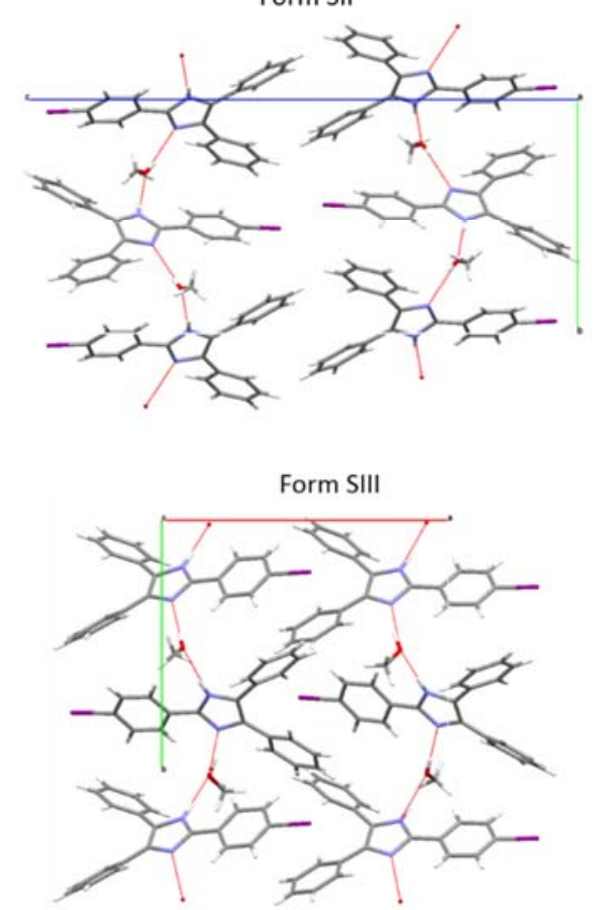

Figure 7. Hydrogen-bonded chains in forms SI, SII and SIII of I-TPI.

The formation of solvates from alcohols and water is known in sterically hindered imidazole derivatives, as the incorporation of solvent allows a greater distance between molecules. ${ }^{40}$ The large aromatic substituents in I-TPI cause the imidazole rings to deviate from co-planarity with one another, as observed in the anhydrous form. In this case, however, the deviation is much greater. Similarly, the I-TPI molecules in solvated forms adopt an alternating arrangement in 
which equivalent substituents are positioned on opposite sides of the chain, further decreasing steric interactions.

The stability relationship between these polymorphs can be deduced from the conditions under which they form. Following formation of the gel, under the correct conditions, crystals of Form II appear first, without disturbing the gel phase. When the gel breaks down, these crystals transform spontaneously into Form SI, which according to Ostwald's rule, implies that Form SI is more stable than Form SII. Form SI can also crystallise directly from the gel phase, concomitant with the gel's break-down, bypassing the formation of Form SII. Crystals of Form SIII also transform into Form SI over time, but despite several attempts, could not be re-grown for thermal analysis. The difficulty encountered in re-growing this form, and the fact that its formation requires heterogeneous nucleation, both imply that it is highly metastable ${ }^{80}$ Given that the packing motif of Form SIII is similar to the other methanol solvates (Fig. 7), it may represent another step in the sequential crystallisation of the I-TPI gel. The high $Z^{\prime}$ of 3 and the metastability of this structure suggest it may appear early on in the sequence and rapidly transform into a more stable polymorph, which is consistent with the difficulty encountered in reproducing this form.

To further probe this stability order, the total packing energy of each form was calculated from its crystal structure, using the UNI intermolecular interactions tool in Mercury, an empirical force field calculation. ${ }^{81-82}$ The calculated energies are given in Table 2, and correlate with the stability of each crystal form, assuming entropic effects are approximately equal. 


\begin{tabular}{llllll}
\hline & Form SI & Form SII & Form SIII & Form V & Form VI \\
\hline Total Packing Energy $/ \mathrm{kJ} \mathrm{mol}^{-1}$ & -229.1 & -222.8 & -225.0 & -189.5 & -190.0
\end{tabular}

Table 2. Calculated total packing energies of Forms I-V of I-TPI

These results show that Form SI has the lowest packing energy of the three solvates, which is to be expected given that it is the most thermodynamically stable under ambient conditions. Form SII has a higher energy than Form SIII, which is the opposite trend to what would be expected based on the crystallisation observations, however, since both crystal structures show higher R-values, these results will have to be taken with care. Form SII has the highest density of the three solvates, which is unusual given its observed metastability, and following the rule of density, this would suggest that this crystal form is the most stable of all three methanol solvates at absolute zero. ${ }^{83}$ It is possible that forms SI and SII show an enantiotropic transition at lower temperatures. The two anhydrous polymorphs, Forms V and VI, have very similar packing energies, which is to be expected given their extremely close structural similarity. 
Relationships between the solvated and anhydrous forms were characterised by DSC (Fig. 8).
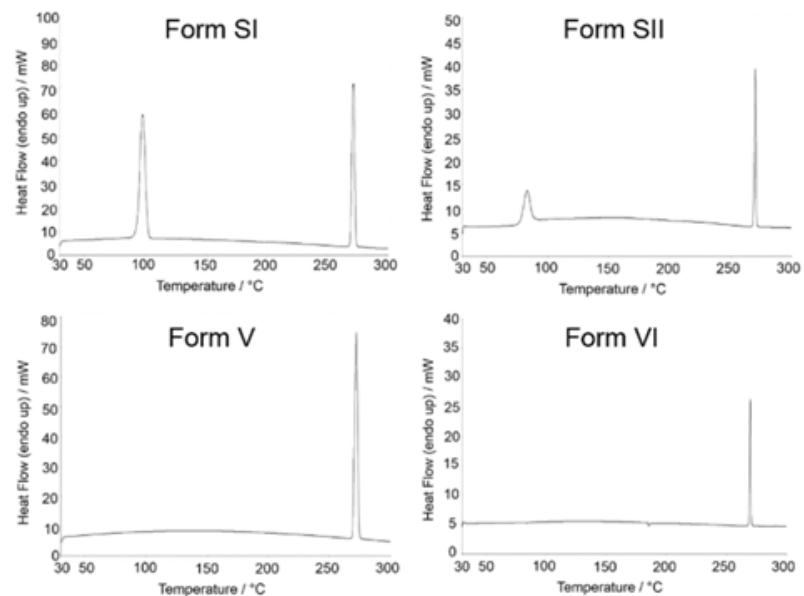

Figure 8. DSC thermograms of Forms SI, SII, V and VI. Peak onset temperatures are as follows: Form SI desolvation $93.95{ }^{\circ} \mathrm{C}$, melt $268.82{ }^{\circ} \mathrm{C}$; Form SII desolvation $78.25{ }^{\circ} \mathrm{C}$, melt $269.04{ }^{\circ} \mathrm{C}$; Form V melt $269.17^{\circ} \mathrm{C}$; Form VI melt $268.79^{\circ} \mathrm{C}$.

The thermograms for Forms SI and SII, the two solvates which were stable enough to analyse, show desolvation peaks at $91{ }^{\circ} \mathrm{C}$ and $77{ }^{\circ} \mathrm{C}$, respectively. These desolvation temperatures are very high, given that the boiling point of methanol is $64{ }^{\circ} \mathrm{C}$, which shows that the solvent is strongly bound into the crystal structure. The structure of the desolvated form was characterised using PXRD, by heating a sample of Forms SI and SII above their transition temperatures. Both experiments showed the presence of Form V after desolvation (Fig. S9). Both solvates SI and SII as well as Form V show a melting endotherm at $269^{\circ} \mathrm{C}$. The DSC thermogram of Form VI, comparable to Form V, shows no reproducible thermal event before the melting point at $269{ }^{\circ} \mathrm{C}$.

The ability of the gel to nucleate the metastable Form SII suggests a small energetic difference and a potential structural similarity between the crystal structure of Form SII and the gel fibre. ${ }^{84}$ Given the importance of one-dimensional intermolecular interactions in supramolecular gelation, ${ }^{11}$ it is likely that the alternating methanol/I-TPI chains comprise the building blocks of 
gel fibres. Kinetic restrictions on packing molecules orthogonal to these chains hence promote one-dimensional fibre formation over three-dimensional crystallisation, on a short timescale, thus producing the supramolecular gel. The powder X-ray diffraction pattern of the dried xerogel is most similar to the calculated pattern from Form SI (Fig. 9).

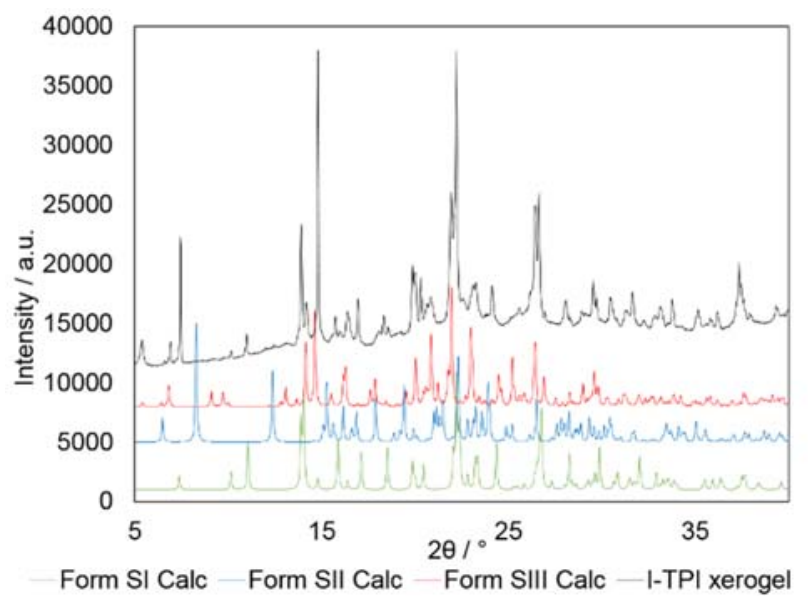

Figure 9. Experimental PXRD patterns of the dried I-TPI xerogel, compared with calculated patterns of metastable methanol solvates, Forms SI-SIII.

This is to be expected, as the gel was left to dry overnight, which allowed time for the metastable gel fibres to begin the transformation into Form SI. However, there are several additional peaks which do not correspond to any known form and suggest that the xerogel does not share its structure with any of the known methanol solvates. The unique structure of the gel is consistent with its role as the first step in the crystallisation regime of I-TPI.

\section{Pharmaceutical Crystallisation}

The ability of the I-TPI gel to selectively crystallise a metastable polymorph of a methanol solvate suggests that this property may be applied to other substrates, and hence that the material may be applicable as a medium for the controlled crystallisation of pharmaceuticals. To investigate this suggestion, diatrizoic acid, DTA, was crystallised within the I-TPI gel (Fig. 10). 
<smiles>CC(=O)Nc1c(I)c(NC(C)=O)c(I)c(C(=O)O)c1I</smiles>

Figure 10. Structure of diatrizoic acid (DTA).

Recent work shows that polymorph control can be achieved by matching the structure of a supramolecular gelator to that of the target drug. ${ }^{84}$ Whilst there are some structural similarities between this drug and gelator, including the iodo- substituent and anti-parallel arrangement of hydrogen bond donor and acceptor groups, in this case I-TPI could not be classed as 'drugmimicking'.

Previous studies of DTA have resulted in the discovery of two hydrates, nine solvates and three anhydrous polymorphs. ${ }^{[41]}$ The strongest intermolecular interaction in all the crystal structures involves the carboxylic acid. ${ }^{85}$ Most commonly, a hydrogen bond is donated to the solvent in an interaction found to be stronger than the halogen bonds in this system. These interactions mirror that of I-TPI, in which hydrogen bonding is dominant. Matching the principal supramolecular motifs of the gelator and drug substrate should further reinforce interactions between the two, in order to facilitate control of solid form.

Various concentrations of the drug, ranging from $1-5 \% \mathrm{w} / \mathrm{v}$, were incorporated into a $2 \% \mathrm{w} / \mathrm{v}$ gel (Table S3). The DTA-containing samples were all found to crystallise in a stepwise manner, forming two distinct crystal habits, over a similar timescale to the crystallisation of the pure ITPI gel. First, all samples grew clusters of small, white needles over the course of one hour to one day. Samples with a higher drug concentration crystallised faster, and those above $3 \% \mathrm{w} / \mathrm{v}$ no longer exhibited gelation but crystallised immediately from solution. If left for a time ranging 
from four days to two weeks, the gel broke down and these needles were replaced by transparent, block-shaped single crystals (Fig. 11). This transformation occurred for every concentration of DTA but, once again, the rate of the change was faster for gels with a higher drug loading.
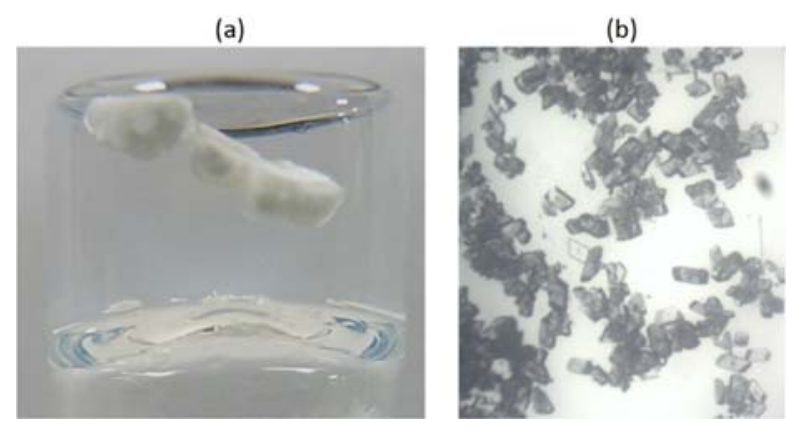

Figure 11. (a) Small needle-like crystals initially grown within a 2\% I-TPI gel containing 2\% DTA. (b) Block-like single crystals formed after break-down of the same gel.

Attempts to determine the single crystal structure or PXRD pattern of the needle-like crystals resulted in amorphous background, and it is possible that these crystals are either too small to show diffraction or that they amorphise when removed from the gel. Solution-state ${ }^{1} \mathrm{H}$ NMR spectroscopy showed that these crystals contain a 2:1 ratio of I-TPI and DTA. However, due to the fast exchange of the carboxylate proton, it is not possible to determine by this method whether the structure is a salt or a co-crystal. Solid-state ${ }^{13} \mathrm{C}$ NMR confirmed the presence of both DTA and I-TPI, and also proved that the structure contains methanol, and is therefore another solvate. To confirm the sample was not simply a mixture of pure crystals of DTA and ITPI, the IR spectrum was measured and compared to those of the two components. The spectrum of the needles was different to both pure compounds, and was not a sum of the two, which proves that they are a distinct crystalline form containing DTA, I-TPI, and methanol (Fig. S10).

Formation of the needle-shaped crystals occurred over a few hours to one day, and was accompanied by breakdown of the gel, due to incorporation of gelator molecules into the 
crystals. Rheological characterisation of the DTA-containing gels was not possible, due to the fast formation of crystallites under the experimental conditions, which subsequently caused the gel to break down. The larger, block-shaped crystals were more stable and were identified by single-crystal X-ray diffraction as a salt solvate, in which the asymmetric unit contains one molecule of a deprotonated DTA anion, one molecule of a protonated I-TPI cation, and two methanol molecules. Whilst this structure contains the same molecules as the needles, the stoichiometry is different. Crystallographic data for this structure can be found in Table S4. The drug and gelator are arranged in hydrogen-bonded chains in an alternating sequence: I-TPI, methanol, DTA (Fig. 12a). Unlike the I-TPI solvates, these chains are connected via hydrogen bonds from methanol in one chain to the carboxylate group of the DTA anion in an adjacent chain (Fig. 12b).

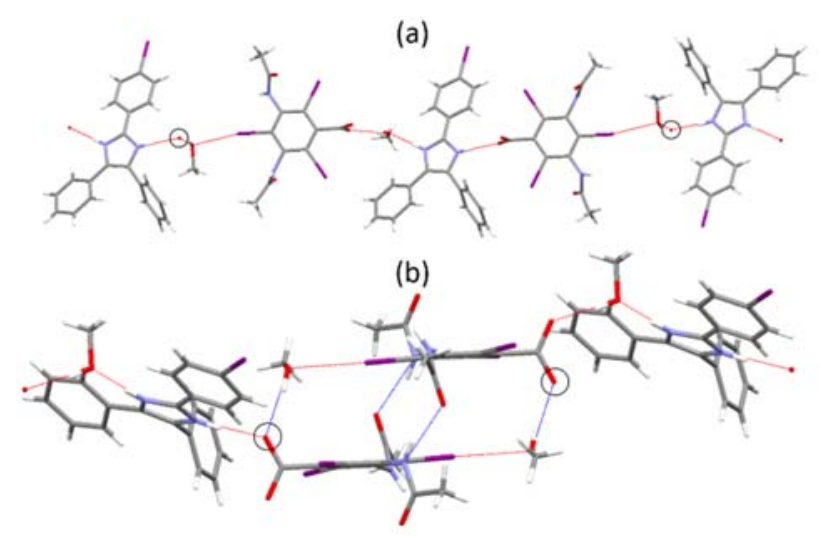

Figure 12. (a) Hydrogen-bonded chains in the I-TPI/DTA/MeOH salt solvate. (b) The hydrogen bonding motif between chains in the I-TPI/DTA/MeOH salt solvate. The black circles in both diagrams show points at which the carbonyl oxygen from DTA forms hydrogen bonds between adjacent chains, linking them together. In diagram (b) the red dashed lines show hydrogen bonds within a chain and the blue dashed lines show hydrogen bonds between chains. 
The multiple hydrogen-bonding groups in DTA facilitate the formation of stacks of DTA molecules orthogonal to the alternating chains. (Fig. 13a). This stacking prompts organisation of I-TPI and DTA into discrete layers (Fig. 13b). This crystal structure demonstrates the formation of a hydrogen bonded network between I-TPI, DTA and methanol; reinforcing the assumption that structural similarity between drug and gelator encourages them to interact.

(a)

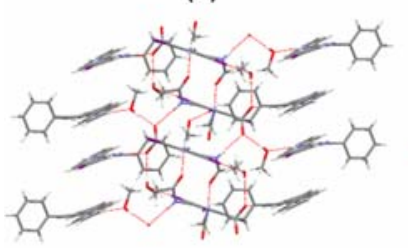

(b)

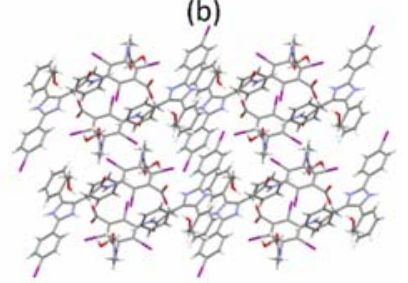

Figure 13. (a) Hydrogen-bonded stacks of DTA molecules (b) Layered packing pattern of the salt solvate structure.

There have been numerous recent examples of pharmaceutical polymorph control techniques in which a gelator selectively generates a known solid form, or facilitates crystallisation of a new one. ${ }^{60,84,86-89}$ In this case, however, a series of solid forms is produced, in the order of increasing thermodynamic stability, according to Ostwald's rule and mirroring the pattern in which the gel itself crystallises without the drug. Gels which can stabilise a metastable polymorph of their gelator may therefore represent a new avenue in the field of pharmaceutical crystallisation, in line with recent suggestions that the function of a supramolecular system is defined more by its energy landscape than the chemical structure of its components..$^{90}$

\section{CONCLUSIONS}

In conclusion, we report the supramolecular gelation behaviour of a mono-iodinated 2,4,5triphenyl imidazole derivative. Gelation is only observed in methanol and is driven by the formation of hydrogen-bonded chains of imidazole and methanol groups. Steric interactions 
between peripheral groups mean that whilst the gel is thermodynamically metastable, it is the most kinetically accessible state in the system. Gelation therefore occurs first, followed by a stepwise crystallisation forming three increasingly stable methanol solvates. Thus the supramolecular gel can be seen as the first stage in the crystallisation regime of the gelator, as described by Ostwald's Rule. Incorporation of a pharmaceutical drug within the gel produces a similar stepwise crystallisation, yielding two increasingly stable solid forms of a drug-gelator salt. This behaviour highlights the possibility of using other gelators which crystallise as a metastable crystal form within the gel network, as a crystallisation medium to access metastable pharmaceutical polymorphs. 


\section{ASSOCIATED CONTENT}

\section{Supporting Information}

The supporting information is available free of charge

The ESI contains further information on the materials and instrumentation used in this study, a synthetic method and structural characterisation of I-TPI, and a detailed gel screening procedure, in addition to the following Figures and Tables (PDF).

Figure S1: Scheme depicting the synthesis of I-TPI

Figure S2: SEM images of a dried, 2\% w/v gel of I-TPI in methanol.

Figure S3: Oscillatory frequency and stress sweep data comparing gels containing $2 \% \mathrm{w} / \mathrm{v}$ and $1.9 \% \mathrm{w} / \mathrm{v} \mathrm{I}$-TPI in methanol.

Figure S4: Oscillatory frequency and stress sweep data comparing gels containing $2 \%-1.6 \%$ w/v I-TPI in methanol. The gels were formed, and the measurements taken at $0^{\circ} \mathrm{C}$.

Figure S5: Oscillatory frequency and stress sweeps for 2\% w/v I-TPI gels in methanol containing $2 \%, 4 \%$ and $6 \% \mathrm{v} / \mathrm{v}$ DMSO.

Figure S6: Oscillatory frequency and stress sweeps for 2\% w/v I-TPI gels in methanol containing $2 \%, 4 \%$ and $6 \% \mathrm{w} / \mathrm{v}$ TBA chloride.

Figure S7: Oscillatory frequency and stress sweeps for 2\% w/v I-TPI gels in methanol containing $2 \%, 4 \%$ and $6 \% \mathrm{v} / \mathrm{v}$ hexane.

Figure S8: Oscillatory frequency and stress sweeps for 2\% w/v I-TPI gels in methanol containing either $2 \% \mathrm{w} / \mathrm{v}$ TBA chloride or $2 \% \mathrm{v} / \mathrm{v}$ DMSO or hexane, compared to the pure $2 \% \mathrm{w} / \mathrm{v}$ gel in 
methanol, showing the increase in shear moduli and yield stress caused by incorporation of the additives.

Figure S9: Experimental PXRD patterns of Forms I and II after their phase transitions, compared to the calculated patterns of Forms IV and V, showing that both forms transform into Form IV after desolvation.

Figure S9: IR spectra of pure I-TPI, pure DTA and the needle shaped co-crystals

Table S1: Gel screening results of I-TPI in methanol.

Table S2: Results of gel testing incorporating additives.

Table S3: Results of gelation screening of mixtures containing $2 \% \mathrm{w} / \mathrm{v}$ I-TPI in methanol and varying concentrations of diatrizoic acid (DTA).

Table S4: Crystallographic data for the salt solvate containing I-TPI and DTA.

\section{Accession Codes}

CCDC 1870806, 1870807, 1870808, 1870809, 1870810 and 1870811 contain the supplementary crystallographic data for this paper. The data can be obtained free of charge from The Cambridge Crystallographic Data Centre via www.ccdc.cam.ac.uk/structures.

\section{AUTHOR INFORMATION}

\section{Corresponding Author}

*Email: k.edkins@qub.ac.uk

\section{ORCID}

Jessica L. Andrews: 0000-0003-1894-2437

Dmitry S. Yufit: 0000-0002-7208-1212

Jonathan W. Steed: 0000-0002-7466-7794

Katharina Edkins: 0000-0002-6885-5457 


\section{Notes}

The authors declare no competing financial interest.

\section{ACKNOWLEDGEMENTS}

We would like to thank Dr David Apperley and Mr. Douglas Carswell for their assistance with solid-state NMR and DSC measurements, respectively. We acknowledge the EPSRC for funding, through the SOFI CDT and Durham University.

\section{REFERENCES}

(1) McNaught, A. D., Compendium of chemical terminology. Blackwell Science Oxford: 1997; Vol. 1669.

(2) Lewis, A.; Seckler, M.; Kramer, H.; van Rosmalen, G., Industrial Crystallization: Fundamentals and Applications. Cambridge University Press: Cambridge, 2015.

(3) Bernstein, J., Fundamentals. In Polymorphism in Molecular Crystals, Clarendon Press: Oxford, 2002; pp 29-65.

(4) Ostwald, W., Studies on formation and transformation of solid materials. Z. Phys. Chem 1897, 22, 289-330.

(5) Thun, J.; Seyfarth, L.; Senker, J.; Dinnebier, R. E.; Breu, J., Polymorphism in Benzamide: Solving a 175-Year-Old Riddle. Angew. Chem. Int. Ed. 2007, 46, 6729-6731.

(6) Levin, A.; Mason, T. O.; Adler-Abramovich, L.; Buell, A. K.; Meisl, G.; Galvagnion, C.; Bram, Y.; Stratford, S. A.; Dobson, C. M.; Knowles, T. P. J.; Gazit, E., Ostwald's rule of stages governs structural transitions and morphology of dipeptide supramolecular polymers. Nat. Commun. 2014, 5, 5219.

(7) Flory, P. J., Introductory lecture. Faraday Disc. Chem. Soc. 1974, 57, 7-18.

(8) Yu, G.; Yan, X.; Han, C.; Huang, F., Characterization of supramolecular gels. Chem. Soc. Rev. 2013, 42, 6697-6722.

(9) Terech, P.; Weiss, R. G., Low Molecular Mass Gelators of Organic Liquids and the Properties of Their Gels. Chem. Rev. 1997, 97, 3133-3159.

(10) Steed, J. W., Supramolecular gel chemistry: developments over the last decade. Chem. Commun. 2011, 47, 1379-1383.

(11) Hanabusa, K.; Yamada, M.; Kimura, M.; Shirai, H., Prominent Gelation and Chiral Aggregation of Alkylamides Derived from trans-1,2-Diaminocyclohexane. Angew. Chem. Int. Ed. 1996, 35, 1949-1951.

(12) Jones, C. D.; Kennedy, S. R.; Walker, M.; Yufit, D. S.; Steed, J. W., Scrolling of supramolecular lamellae in the hierarchical self-assembly of fibrous gels. Chem 2017.

(13) Fages, F.; Vögtle, F.; Žinic, M., Systematic Design of Amide- and Urea-Type Gelators with Tailored Properties. In Low Molecular Mass Gelator, Springer Berlin Heidelberg: Berlin, Heidelberg, 2005; pp 77-131. 
(14) Dastidar, P., Supramolecular gelling agents: can they be designed? Chem. Soc. Rev. 2008, 37, 2699-2715.

(15) Kumar, D. K.; Steed, J. W., Supramolecular gel phase crystallization: orthogonal selfassembly under non-equilibrium conditions. Chem. Soc. Rev. 2014, 43, 2080-8.

(16) Ramos Sasselli, I.; Halling, P. J.; Ulijn, R. V.; Tuttle, T., Supramolecular Fibers in Gels Can Be at Thermodynamic Equilibrium: A Simple Packing Model Reveals Preferential Fibril Formation versus Crystallization. ACS Nano 2016, 10, 2661-2668.

(17) Adams, D. J.; Morris, K.; Chen, L.; Serpell, L. C.; Bacsa, J.; Day, G. M., The delicate balance between gelation and crystallisation: structural and computational investigations. Soft Matter 2010, 6, 4144-4156.

(18) Moffat, J. R.; Smith, D. K., Metastable two-component gel-exploring the gel-crystal interface. Chem. Commun. 2008, 2248-2250.

(19) Zhu, P.; Yan, X.; Su, Y.; Yang, Y.; Li, J., Solvent-Induced Structural Transition of SelfAssembled Dipeptide: From Organogels to Microcrystals. Chem. Eur. J. 2010, 16, 31763183.

(20) Terech, P.; Sangeetha, N. M.; Maitra, U., Molecular Hydrogels from Bile Acid Analogues with Neutral Side Chains: Network Architectures and Viscoelastic Properties. Junction Zones, Spherulites, and Crystallites: Phenomenological Aspects of the Gel Metastability. J. Phys. Chem. B 2006, 110, 15224-15233.

(21) Lebel, O.; Perron, M.-È.; Maris, T.; Zalzal, S. F.; Nanci, A.; Wuest, J. D., A New Class of Selective Low-Molecular-Weight Gelators Based on Salts of Diaminotriazinecarboxylic Acids. Chem. Mater. 2006, 18, 3616-3626.

(22) Houton, K. A.; Morris, K. L.; Chen, L.; Schmidtmann, M.; Jones, J. T. A.; Serpell, L. C.; Lloyd, G. O.; Adams, D. J., On Crystal versus Fiber Formation in Dipeptide Hydrogelator Systems. Langmuir 2012, 28, 9797-9806.

(23) Roy, B.; Bairi, P.; Nandi, A. K., Metastability in a bi-component hydrogel of thymine and 6-methyl-1,3,5-triazine-2,4-diamine: ultrasound induced vs. thermo gelation. Soft Matter 2012, 8, 2366-2369.

(24) Kapoor, I.; Schon, E.-M.; Bachl, J.; Kuhbeck, D.; Cativiela, C.; Saha, S.; Banerjee, R.; Roelens, S.; Marrero-Tellado, J. J.; Diaz, D. D., Competition between gelation and crystallisation of a peculiar multicomponent liquid system based on ammonium salts. Soft Matter 2012, 8, 3446-3456.

(25) Aiyappa, H. B.; Saha, S.; Garai, B.; Thote, J.; Kurungot, S.; Banerjee, R., A Distinctive PdCl2-Mediated Transformation of Fe-Based Metallogels into Metal-Organic Frameworks. Cryst. Growth Des. 2014, 14, 3434-3437.

(26) Liu, J.; Xu, F.; Sun, Z.; Pan, Y.; Tian, J.; Lin, H.-C.; Li, X., A supramolecular gel based on a glycosylated amino acid derivative with the properties of gel to crystal transition. Soft Matter 2016, 12, 141-148.

(27) Wang, Y.; Tang, L.; Yu, J., Investigation of Spontaneous Transition from Low-MolecularWeight Hydrogel into Macroscopic Crystals. Cryst. Growth Des. 2008, 8, 884-889.

(28) Barker, E. C.; Martin, A. D.; Garvey, C. J.; Goh, C. Y.; Jones, F.; Mocerino, M.; Skelton, B. W.; Ogden, M. I.; Becker, T., Thermal annealing behaviour and gel to crystal transition of a low molecular weight hydrogelator. Soft Matter 2017, 13, 1006-1011.

(29) Guo, M.; Yin, Q.; Li, Y.; Huang, Y.; Zhang, Z.; Zhou, L., Gel-Crystal Transition during Crystallization of Cefpiramide. Chem. Lett. 2017, 46, 1292-1295. 
(30) Shi, Z.; Hao, L.; Zhang, M.; Dang, L.; Wei, H., Gel formation and transformation of Moxidectin during the anti-solvent crystallization. J. Cryst. Growth 2017, 469, 8-12.

(31) Nakashima, K., Lophine derivatives as versatile analytical tools. Biomed. Chromatogr. 2003, 17, 83-95.

(32) White, E. H.; Harding, M. J. C., The Chemiluminescence of Lophine and Its Derivatives. J. Am. Chem. Soc. 1964, 86, 5686-5687.

(33) White, D. M.; Sonnenberg, J., Oxidation of Triarylimidazoles. Structures of the Photochromic and Piezochromic Dimers of Triarylimidazyl Radicals1. J. Am. Chem. Soc. 1966, 88, 3825-3829.

(34) Kishimoto, Y.; Abe, J., A Fast Photochromic Molecule That Colors Only under UV Light. J. Am. Chem. Soc. 2009, 131, 4227-4229.

(35) Yamashita, H.; Abe, J., Photochromic Properties of [2.2]Paracyclophane-Bridged Imidazole Dimer with Increased Photosensitivity by Introducing Pyrenyl Moiety. J. Phys. Chem. A 2011, 115, 13332-13337.

(36) Edkins, R. M.; Probert, M. R.; Robertson, C. M.; Howard, J. A. K.; Beeby, A., Photocrystallisation of the $2 \mathrm{C}-2^{\prime} \mathrm{C}$ dimer of a triphenylimidazolyl radical. RSC Adv. 2014, 4, 5351-5356.

(37) Kitchen, T.; Melvin, C.; Mohd Najib, M. N.; Batsanov, A. S.; Edkins, K., Influence of BioIsosteric Replacement on the Formation of Templating Methanol and Acetonitrile Solvates in Lophines. Cryst. Growth Des. 2016, 16, 4531-4538.

(38) Edkins, R. M.; Probert, M. R.; Fucke, K.; Robertson, C. M.; Howard, J. A. K.; Beeby, A., The formation of peroxide degradation products of photochromic triphenylimidazolyl radical-dimers. Phys. Chem. Chem. Phys. 2013, 15, 7848-7853.

(39) Martinez-Carrera, S., The crystal structure of imidazole at -150degreesC. Acta Crystallogr. 1966, 20, 783-789.

(40) Cammers, A.; Parkin, S., Solid state hydrogen bonding in imidazole derivatives: a persistent tape motif. CrystEngComm 2004, 6, 168-172.

(41) Ballabh, A.; Trivedi, D. R.; Dastidar, P., Structural Studies of a New Low Molecular Mass Organic Gelator for Organic Liquids Based on Simple Salt. Chem. Mat. 2003, 15, 21362140.

(42) Seo, S. H.; Chang, J. Y., Organogels from 1H-Imidazole Amphiphiles: Entrapment of a Hydrophilic Drug into Strands of the Self-Assembled Amphiphiles. Chem. Mater. 2005, 17, 3249-3254.

(43) James, S. J.; Perrin, A.; Jones, C. D.; Yufit, D. S.; Steed, J. W., Highly interlocked anionbridged supramolecular networks from interrupted imidazole-urea gels. Chem. Commun. 2014, 50, 12851-12854.

(44) Mondal, S.; Ghosh, K., Anthraquinone Derived Cholesterol Linked Imidazole Gelator in Visual Sensing of Picric Acid. ChemistrySelect 2017, 2, 4800-4806.

(45) Jones, C. D.; Steed, J. W., Gels with sense: supramolecular materials that respond to heat, light and sound. Chem. Soc. Rev. 2016, 45, 6546-6596.

(46) Adams, D., Does Drying Affect Gel Networks? Gels 2018, 4, 32.

(47) Mears, L. L.; Draper, E. R.; Castilla, A. M.; Su, H.; Dietrich, B.; Nolan, M. C.; Smith, G. N.; Doutch, J.; Rogers, S.; Akhtar, R., Drying affects the fiber network in low molecular weight hydrogels. Biomacromolecules 2017, 18, 3531-3540.

(48) Almdal, K.; Dyre, J.; Hvidt, S.; Kramer, O., Towards a phenomenological definition of the term 'gel'. Polym. Gels Networks 1993, 1, 5-17. 
(49) Goodwin, J. W.; Hughes, R. W., Rheology for chemists: an introduction. Royal Society of Chemistry: 2008.

(50) Shtukenberg, A. G.; Lee, S. S.; Kahr, B.; Ward, M. D., Manipulating Crystallization with Molecular Additives. Annu. Rev. Chem. Biomol. Eng. 2014, 5, 77-96.

(51) Rodríguez-hornedo, N.; Murphy, D., Significance of controlling crystallization mechanisms and kinetics in pharmaceutical systems. J. Pharm. Sci. 1999, 88, 651-660.

(52) Shtukenberg, A. G.; Ward, M. D.; Kahr, B., Crystal Growth with Macromolecular Additives. Chem. Rev. 2017, 117, 14042-14090.

(53) Clydesdale, G.; Roberts, K. J.; Docherty, R., Modelling the morphology of molecular crystals in the presence of disruptive tailor-made additives. J. Cryst. Growth 1994, 135, 331-340.

(54) Dowling, R.; Davey, R. J.; Curtis, R. A.; Han, G.; Poornachary, S. K.; Chow, P. S.; Tan, R. B. H., Acceleration of crystal growth rates: an unexpected effect of tailor-made additives. Chem. Commun. 2010, 46, 5924-5926.

(55) L. W. Griffin, J.; V. Coveney, P.; Whiting, A.; Davey, R., Design and synthesis of macrocyclic ligands for specific interaction with crystalline ettringite and demonstration of a viable mechanism for the setting of cement. J. Chem. Soc., Perkin Trans. 2 1999, 1973 1981.

(56) Poornachary, S. K.; Chow, P. S.; Tan, R. B.; Davey, R. J., Molecular speciation controlling stereoselectivity of additives: impact on the habit modification in $\alpha$-glycine crystals. Cryst. Growth Des. 2007, 7, 254-261.

(57) Buerkle, L. E.; Rowan, S. J., Supramolecular gels formed from multi-component low molecular weight species. Chem. Soc. Rev. 2012, 41, 6089-6102.

(58) Lan, Y.; Corradini, M. G.; Weiss, R. G.; Raghavan, S. R.; Rogers, M. A., To gel or not to gel: correlating molecular gelation with solvent parameters. Chem. Soc. Rev. 2015, 44, 6035-6058.

(59) Terech, P.; Pasquier, D.; Bordas, V.; Rossat, C., Rheological Properties and Structural Correlations in Molecular Organogels. Langmuir 2000, 16, 4485-4494.

(60) Foster, J. A.; Piepenbrock, M.-O. M.; Lloyd, G. O.; Clarke, N.; Howard, J. A. K.; Steed, J. W., Anion-switchable supramolecular gels for controlling pharmaceutical crystal growth. Nat Chem 2010, 2, 1037-1043.

(61) Lloyd, G. O.; Piepenbrock, M.-O. M.; Foster, J. A.; Clarke, N.; Steed, J. W., Anion tuning of chiral bis(urea) low molecular weight gels. Soft Matter 2012, 8, 204-216.

(62) Piepenbrock, M.-O. M.; Clarke, N.; Foster, J. A.; Steed, J. W., Anion tuning and polymer templating in a simple low molecular weight organogelator. Chem. Commun. 2011, 47, 2095-2097.

(63) Piepenbrock, M.-O. M.; Lloyd, G. O.; Clarke, N.; Steed, J. W., Gelation is crucially dependent on functional group orientation and may be tuned by anion binding. Chem. Commun. 2008, 2644-2646.

(64) Buerkle, L. E.; Galleguillos, R.; Rowan, S. J., Nonionic surfactant-induced stabilization and tailorability of sugar-amphiphile hydrogels. Soft Matter 2011, 7, 6984-6990.

(65) Way, A. E.; Korpusik, A. B.; Dorsey, T. B.; Buerkle, L. E.; von Recum, H. A.; Rowan, S. J., Enhancing the Mechanical Properties of Guanosine-Based Supramolecular Hydrogels with Guanosine-Containing Polymers. Macromolecules 2014, 47, 1810-1818. 
(66) Adhia, Y. J.; Schloemer, T. H.; Perez, M. T.; McNeil, A. J., Using polymeric additives to enhance molecular gelation: impact of poly(acrylic acid) on pyridine-based gelators. Soft Matter 2012, 8, 430-434.

(67) Brizard, A. M.; Stuart, M. C. A.; van Esch, J. H., Self-assembled interpenetrating networks by orthogonal self assembly of surfactants and hydrogelators. Faraday Discus. 2009, 143, 345-357.

(68) Offiler, C. A.; Jones, C. D.; Steed, J. W., Metal 'turn-off', anion 'turn-on' gelation cascade in pyridinylmethyl ureas. Chem. Commun. 2017, 53, 2024-2027.

(69) Byrne, P.; Lloyd, G. O.; Applegarth, L.; Anderson, K. M.; Clarke, N.; Steed, J. W., Metalinduced gelation in dipyridyl ureas. New J. Chem. 2010, 34, 2261-2274.

(70) Becker, T.; Yong Goh, C.; Jones, F.; McIldowie, M. J.; Mocerino, M.; Ogden, M. I., Proline-functionalised calix[4]arene: an anion-triggered hydrogelator. Chem. Commun. 2008, 3900-3902.

(71) Hofmeister, F., Zur Lehre von der Wirkung der Salze. N-S Arch. Pharmacol. 1888, 24, 247-260.

(72) Kunz, W.; Henle, J.; Ninham, B. W., 'Zur Lehre von der Wirkung der Salze' (about the science of the effect of salts): Franz Hofmeister's historical papers. Curr. Opin. Colloid Interface Sci. 2004, 9, 19-37.

(73) $\mathrm{Yu}, \mathrm{L}$., Survival of the fittest polymorph: how fast nucleater can lose to fast grower. CrystEngComm 2007, 9, 847-851.

(74) Kempster, C. J. E.; Lipson, H., A rapid method for assessing the number of molecules in the unit cell of an organic crystal. Acta Crystallogr. B 1972, 28, 3674.

(75) Ueda, T.; Nagatomo, S.; Masui, H.; Nakamura, N.; Hayashi, S., Hydrogen bonds in crystalline imidazoles studied by $15 \mathrm{~N}$ NMR and ab initio MO calculations. Z. Natuforsch. A 1999, 54, 437-442.

(76) Steed, K. M.; Steed, J. W., Packing Problems: High Z' Crystal Structures and Their Relationship to Cocrystals, Inclusion Compounds, and Polymorphism. Chem. Rev. 2015, 115, 2895-2933.

(77) Anderson, K. M.; Probert, M. R.; Whiteley, C. N.; Rowland, A. M.; Goeta, A. E.; Steed, J. W., Designing Co-Crystals of Pharmaceutically Relevant Compounds That Crystallize with Z' > 1. Cryst. Growth Des. 2009, 9, 1082-1087.

(78) Bond, A. D.; Boese, R.; Desiraju, G. R., On the Polymorphism of Aspirin: Crystalline Aspirin as Intergrowths of Two "Polymorphic" Domains. Angew. Chem. Int. Ed. 2007, 46, 618-622.

(79) Fucke, K.; Anderson, K. M.; Filby, M. H.; Henry, M.; Wright, J.; Mason, S. A.; Gutmann, M. J.; Barbour, L. J.; Oliver, C.; Coleman, A. W., The Structure of Water in pSulfonatocalix [4] arene. Chem. Eur. J. 2011, 17, 10259-10271.

(80) Dunitz, J. D.; Bernstein, J., Disappearing Polymorphs. Acc. Chem. Res. 1995, 28, 193-200.

(81) Gavezzotti, A., The Crystal Packing of Organic Molecules: Challenge and Fascination Below 1000 Da. Crystallogr. Rev. 1998, 7, 5-121.

(82) Gavezzotti, A., Are Crystal Structures Predictable? Acc. Chem. Res. 1994, 27, 309-314.

(83) Burger, A.; Ramberger, R., On the polymorphism of pharmaceuticals and other molecular crystals. II. Microchim. Acta 1979, 72, 273-316.

(84) Foster, J. A.; Damodaran, K. K.; Maurin, A.; Day, G. M.; Thompson, H. P. G.; Cameron, G. J.; Bernal, J. C.; Steed, J. W., Pharmaceutical polymorph control in a drug-mimetic supramolecular gel. Chem. Sci. 2017, 8, 78-84. 
(85) Fucke, K.; McIntyre, G. J.; Lemée-Cailleau, M.-H.; Wilkinson, C.; Edwards, A. J.; Howard, J. A. K.; Steed, J. W., Insights into the Crystallisation Process from Anhydrous, Hydrated and Solvated Crystal Forms of Diatrizoic Acid. Chem. Eur. J. 2015, 21, 10361047.

(86) Kaufmann, L.; Kennedy, S. R.; Jones, C. D.; Steed, J. W., Cavity-containing supramolecular gels as a crystallization tool for hydrophobic pharmaceuticals. Chem. Commun. 2016, 52, 10113-10116.

(87) Ruiz-Palomero, C.; Kennedy, S. R.; Soriano, M. L.; Jones, C. D.; Valcarcel, M.; Steed, J. W., Pharmaceutical crystallization with nanocellulose organogels. Chem. Commun. 2016, 52, 7782-7785.

(88) Buendía, J.; Matesanz, E.; Smith, D. K.; Sánchez, L., Multi-component supramolecular gels for the controlled crystallization of drugs: synergistic and antagonistic effects. CrystEngComm 2015, 17, 8146-8152.

(89) Aparicio, F.; Matesanz, E.; Sanchez, L., Cooperative self-assembly of linear organogelators. Amplification of chirality and crystal growth of pharmaceutical ingredients. Chem. Commun. 2012, 48, 5757-5759.

(90) Tantakitti, F.; Boekhoven, J.; Wang, X.; Kazantsev, R. V.; Yu, T.; Li, J.; Zhuang, E.; Zandi, R.; Ortony, J. H.; Newcomb, C. J.; Palmer, L. C.; Shekhawat, G. S.; de la Cruz, M. O.; Schatz, G. C.; Stupp, S. I., Energy landscapes and functions of supramolecular systems. Nature Mater. 2016, 15, 469. 


\section{For Table of Contents Use Only}

Supramolecular gelation as the first stage in Ostwald's rule

Jessica L. Andrews, Emma Pearson, Dmitry S. Yufit, Jonathan W. Steed and Katharina Edkins

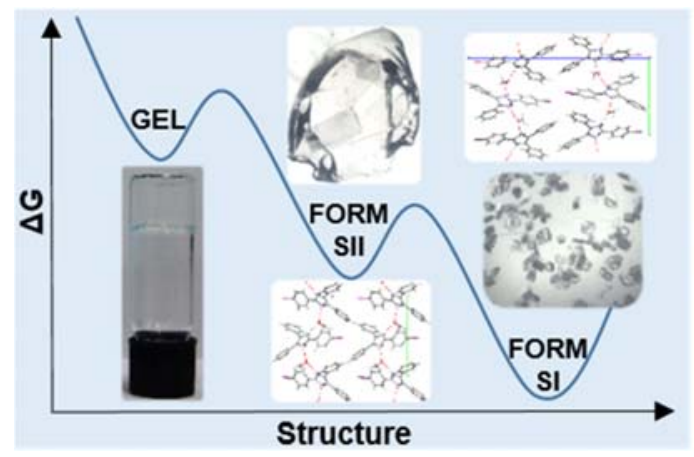

A crystallisation cascade: a sterically hindered lophine gelator is shown to crystallise as a series of increasingly stable solvates. Structurally distinct from each of these polymorphs, the gel emerges as a kinetically trapped intermediate and may therefore be considered the first stage in the crystallisation regime of the gelator, as described by Ostwald's rule. 